\title{
Two-parametric analysis of the Weibull distribution strength of advanced ceramics materials
}

\author{
Mateusz Wirwicki ${ }^{1, *}$ \\ ${ }^{1}$ UTP University of Science and Technology, Faculty of Mechanical Engineering, Department of \\ Biomedical Engineering, Al. prof. S. Kaliskiego 7, 85-796 Bydgoszcz, Poland
}

\begin{abstract}
Zirconium dioxide is a material known over 60 years, used for the production of ceramic and hybrid bearings and in dentistry: bows, crowns, and bridges. For testing the strength of zirconium dioxide, normative samples were made, which were subjected to strength tests. Microscopic analysis of sample fracture was performed. In addition, zirconium oxide is an easy to process material. Zirconium dioxide is a polymorphic material exhibiting three phases: monocyclic, cubic and tetragonal. In addition, during propagation of cracks, the material shows a strengthening transformation; replacement of phase and increase of the volume of molecules that inhibit microcracks in the material. For a better illustration of the destruction of the samples, a two-parameter analysis of the Weibull distribution was made, which, as shown in the literature review for this type of research is standard. This analysis is described in the standard related to statistical analysis of advanced ceramics. The paper presents the original technology of making zirconium dioxide samples, tests of strength on a servo-hydraulic machine Instron 8874 and microscopic analysis of the obtained results.
\end{abstract}

\section{Introduction}

Advanced ceramic is a material that is used in everyday life. It exhibits its large share in such industries as: medicine, mechanics and construction. It is a highly durable material, having low coefficients of friction and thermal expansion. Very good biocompatibility and translucency. During the research and fabrication of different parts of machines, you need knowledge about the possibility of material survival and estimation of the strength of advanced ceramics, the Weibull's factor. The Weibull module, otherwise called the shape parameter, is taken as an indicator of the variability of material strength. It was noted that the higher the value of the Weibull shape parameter, the greater the clinical reliability. The Weibull distribution is a fault probability distribution model and an analysis of the estimated parameters of this distribution $[1,2]$.

Analysis of the test results presented by the authors of the article indicates a lower resistance to cracking in a liquid environment. The research presented in $[2,3]$ shows that one of the best materials is yttria-stabilized zirconia, characterized by the highest mechanical strength. A two-parametric Weibull distribution was used for the analysis,

\footnotetext{
*Corresponding author: wirwicki@utp.edu.pl
} 
allowing to estimate the probability of material destruction. According to the authors of the article, the design of bridges consisting of only 3 points (from 3 crowns in a curve) should be made of different material than ceramic, and arches consisting of 4 and more - zirconium dioxide. This is related to the physicochemical properties of zirconia - phase changes at room temperature. They are responsible for increasing the grain volume, and thus reducing the crack fractures and the energy that causes the fracture.

Another article referring to ceramics research this time without addition of yttrium oxide is [5], in which static four-point bending tests according to DIN EN 843-1 are presented. 8 groups of 30 samples were prepared, each with nominal dimensions: $1.7 \times 3.2 \times 30 \mathrm{~mm}$. The materials used for the research were: Cerec Mark II (CM), Dicor (D), In-Cream Alumina (ICA), IPS Empress (IE), Vitadur Alpha Core (VAC), Vitadur Alpha Dentin (VAD), Vita VMK 68 ( VMK), Zirconia-TZP (Z). All samples were polished with sandpaper of basis weight: $320,600,1200,4000$. After polishing the samples obtained nominal dimensions: $1.5 \times 3 \times 30 \mathrm{~mm}$. The research results indicate that most materials are characterized by the Weibull module $\mathrm{m}$ in the 5-15 range. Two materials: Cerec Mark II and Zirconia-TZP show a larger Weibull module m, 23.6 and 18.4, respectively. The use of materials characterized by a larger Weibull module and higher durability will result in increased reliability of crowns and bridges of dental arches. Studies have therefore shown a clear advantage of zirconia ceramics over other materials.

The article [6] presents tests of resistance to three-point bending of another commercial variety of zirconium dioxide. The first test used 80 samples divided into 4 groups of 20 samples processed using the device and CAD / CAM software. The tests were carried out on an Instron 8,500 testing machine at an actuator speed of $1 \mathrm{~mm} / \mathrm{min}$. The results were developed statistically using a two-parameter Weibull distribution analysis. These results indicate a very large impact on the strength of ceramics zirconium dioxide preparation procedures.

Based on the literature review, I proposed our own method for producing normative samples and mini. To implement our own research, I used devices that were designed and made by the author of the work. The following materials were used for the tests: zirconium dioxide (Lava, Cercon, Zirkonzahn). The choice of these materials was dictated by their most common use in the construction of machines, dentistry and construction. Also, durability and strength tests are carried out for other advanced materials, e.g. composites or metals with other chemical compositions [7].

The aim of this work is to determine the strength of all-ceramic material, microscopic analysis of the materials under test and the risk and probability of damage to the advanced ceramics.

\section{Materials and methods}

Three ceramic materials with the trade names Zirconia Lava from 3M ESPE, Prettau Zirkon from Zirkonzahn and Cercon from DeguDent were used for the research. These materials are used in dentistry and in the manufacture of ceramic machine bearings (all-ceramic or hybrid). The materials provided by the manufacturer were delivered in the form of unsterized blocks or discs for Zirconia Lava, $60 \times 25 \times 16 \mathrm{~mm}$ blocks, Prettau discs with a diameter of $95 \times 16 \mathrm{~mm}$ and Cercon discs with a diameter of $105 \times 20 \mathrm{~mm}$. The obtained material was unhardened which allowed for free processing. 90 samples for each of the materials were made for the tests. For normative samples compliant with the PN-EN 843-1 standard called Technical advanced ceramics: Mechanical properties of monolithic ceramics at room temperature. Part 1: Determination of bending strength consisting of three processes: cutting of material, grinding and milling. The Buehler ISOMET 5000 circular saw was used to cut material from blocks and discs. The device has a special mounting - sheet fixed to the 
nut bolt, thanks to which the machined surface is parallel to the cutting disc. The device also has an implemented program adjusting the amount of coolant, feed and speed depending on the material being processed. The device allows you to adapt the program to the type of material. The following machining parameters were applied: the speed of rotation of the cutting blade was $4950 \mathrm{rpm}$ and the feed was $19.0 \mathrm{~mm} / \mathrm{min}$. With these settings, the material was cut into strips with a nominal thickness of $2 \mathrm{~mm}$. The final machining was carried out using the Mazak Vertical Center Smart 430A milling machine.

Modern materials used in medicine and machine building are characterized by significant shrinkage during the curing process - sintering. According to manufacturers (Zircon Lava from 3M ESPE, Prettau Zirkon from ZirkonZahn and Cercon from DeguDent), the technological contraction is around $20 \%$, so when designing machine parts or medical applications, you need to give the right amount of material. The next stage of the whole process is sending samples to a certified producer's laboratory where sintering (curing) takes place. The samples are put into an induction furnace at $1410^{\circ} \mathrm{C}$ for 8 hours. The snow-white material after firing shows a marked increase in parameters related to mechanical properties. Fig. 1 shows the geometry of the tested samples after the sintering process, the average dimensions of which were approximately $2 \times 2.5 \times 25 \mathrm{~mm}$.

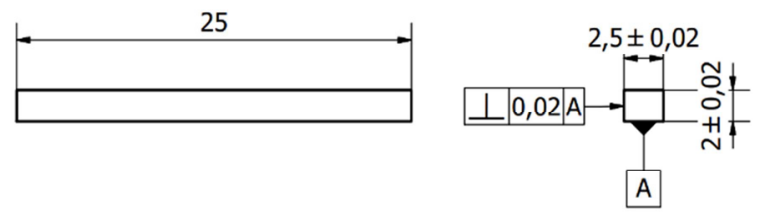

Fig. 1. The geometry of the sample that was made using the author's original method.

During the tests, an Instron 8874 servo-hydraulic testing machine was used with strength and moment, respectively: $\pm 25 \mathrm{kN}, \pm 100 \mathrm{Nm}$. Sample height max. $100 \mathrm{~mm}$ and a rotation angle of $130^{\circ}$.

The device for three- and four-point bending has been designed and made in accordance with the recommendations of the PN-EN 843-1 standard. The rollers on which the test sample is based and which load is applied have been made of hardened steel with a hardness above $40 \mathrm{HRC}$. Their diameter should be approximately $1.6 \mathrm{x}$ the thickness of the sample, which gives the recommended range between 2.2-2.5 mm. Adjustable supports on the handle allow for testing samples from $5 \mathrm{~mm}$ to $45 \mathrm{~mm}$ long. The instrument can be used for three-point and four-point bending tests. The device has $\varnothing 12 \mathrm{~mm}$ fixing bolts, which can be axially gripped in the jaws of the testing machine.

After the mechanical examinations were completed, the Hitachi SU3500 scanning microscope was used to better expose the destruction of the damaged material.

\section{Weibull Analysis}

To better illustrate the destruction of the samples, a two-parameter analysis of the Weibull distribution was performed, which, as can be seen from the literature review for this type of research, is a standard. This analysis is described in the standard related to statistical analysis of advanced ceramics. The analysis was carried out for the results of 3-point bending strength tests for the geometry of all manufacturers (Zircon Lava from 3M ESPE, Prettau Zircon from Zirkonzahn and Cercon from DeguDent) according to PN-EN 843-5: 2007. This standard specifies the statistical analysis of strength data of ceramic materials, in the form of a two-parameter Weibull distribution, using the technique of estimating the maximum probability of destruction. The following formula was used for the analysis: 


$$
P_{f}=1-\exp \left[-N\left(\frac{\sigma-\sigma_{u}}{\sigma_{0}}\right)^{m}\right]
$$

where:

$\sigma$ - destructive load $[\mathrm{MPa}]$

$\sigma_{0}-$ scale parameter,

$\mathrm{m}$ - shape parameter,

$\sigma_{u}$ - position parameter,

e - constant $(\mathrm{e}=2,718 \ldots)$

$P_{f}$ - the probability of destruction.

\section{Results}

Three-point bending tests were performed on a servo-hydraulic testing machine Instron $8874 \mathrm{v}$ using a strain gauge of the same company, with a load range of $\pm 5 \mathrm{kN}$. The tests were carried out on a previously designed and made holder for three- and four-point bending. For testing conducted in accordance with PN-EN 843-1, a sample group of 30 for each manufacturer was used. The sample geometry was $2 \times 2.5 \times 25 \mathrm{~mm}$. The speed of the testing machine actuator was $0.5 \mathrm{~mm} / \mathrm{min}$. According to the standard, the loaded sample should be destroyed within 5-15 s. The resistance to three-point bending is calculated from the formula:

$$
\sigma_{f}=\frac{3 F l}{2 b h^{2}}
$$

where:

$\mathrm{F}$ - maximum force to broke $[\mathrm{N}]$,

b - the mean of the three determinations of the width of the sample [mm],

$\mathrm{h}$ - the average of the three determinations of the thickness of the sample [mm],

1 - the distance between the centers of the outer supporting rollers [mm].

Table 1 shows the results of monotonic three-point bending for Zirkonzahn, Cercon and Lava materials. The results of the Zirkonzahn test are as follows: average bending strength 900.39 MPa, standard deviation $151.83 \mathrm{MPa}$ and relative standard deviation $16,8 \%$. For Cercon: average bending strength $802.18 \mathrm{MPa}$, standard deviation $186.33 \mathrm{MPa}$ and relative standard deviation $23.22 \%$. For Lava: average bending strength $985.57 \mathrm{MPa}$, standard deviation $182.87 \mathrm{MPa}$ and relative standard deviation $18.55 \%$. It is worth noting that these tests were conducted for normative samples in cooperation with prof. $\mathrm{PhD}$ hab. n. med. Wiesław Hędzelek and medicine. dent. Adam Piosik from the Medical University. Karol Marcinkowski in Poznań, Faculty of Medicine II, Prosthodontic Clinic.

Table 1. Results of monotonic three-point bending.

\begin{tabular}{|c|c|c|c|}
\hline Material & $\begin{array}{c}\text { Medium bending } \\
\text { strength [MPa] }\end{array}$ & $\begin{array}{c}\text { Standard deviation } \\
{[\mathbf{M P a}]}\end{array}$ & $\begin{array}{c}\text { Relative standard } \\
\text { deviation [\%] }\end{array}$ \\
\hline Zirkonzahn & 900.39 & 151.83 & 16.86 \\
\hline Cercon & 802.18 & 186.33 & 23.22 \\
\hline Lava & 985.57 & 182.87 & 18.55 \\
\hline
\end{tabular}

Weibull analysis of the results for samples was performed, which is presented in Table 2. It presents the sample size $\mathrm{N}$, the characteristic strength $\sigma 0, \mathrm{R} 2$ and the m module. 
Table 2. Results of Weibull distribution analysis.

\begin{tabular}{|c|c|c|c|c|}
\hline Material & $\mathbf{N}$ & $\boldsymbol{\sigma 0}[\mathbf{M P a}]$ & $\mathbf{R 2}$ & $\mathbf{m}$ \\
\hline Cercon & 30 & 888.68 & 0.9754 & 7.3 \\
\hline Zirkonzahn & 30 & 969.96 & 0.969 & 8.4 \\
\hline Lava & 30 & 1068.30 & 0.961 & 12.1 \\
\hline
\end{tabular}

Fig. 2 presents an approximation of the probability distribution of the three-point bending strength for the three analyzed materials together with values of $\mathrm{R} 2$ determination coefficient for individual materials.

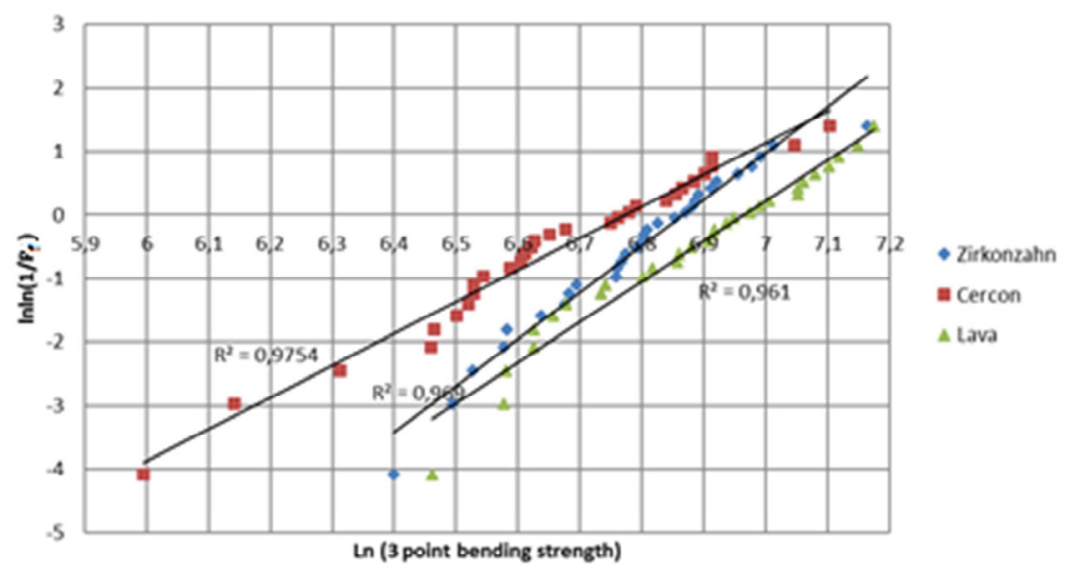

Fig. 2. Approximation of probability distribution of resistance to three-point bending.

Fig. 3 shows the distribution of Weibull distribution for the studied materials. The characteristic value of $63.3 \%$ was also marked, for which the strength according to the analysis is $\sigma_{0}=1068,30 \mathrm{MPa}$ for Lava, $\sigma_{0}=888.68 \mathrm{MPa}$ for Cercon, $\sigma_{0}=969.96 \mathrm{MPa}$ for Zirkonzahn. The use of materials characterized by a larger Weibull module and higher durability will result in increased reliability.



Fig. 3. Distribuser Weibull distribution for zirconia due to bending strength. 
Photos of the tested samples were made with the Hitachi SU3500 Electronic Microscope. Fig. 4 shows sample photos of the structure of fractures of samples made of zirconium dioxide. The research showed that during the three-point bending of zirconium beams the crack initiation point is characterized by increased roughness.

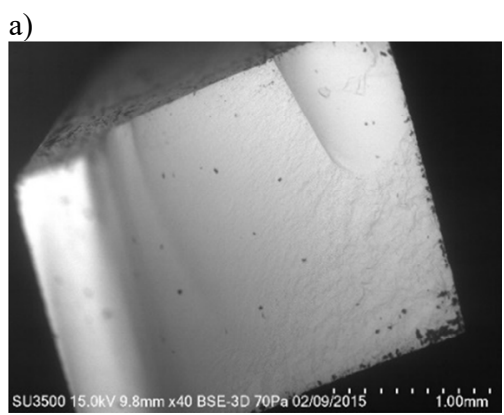

c)

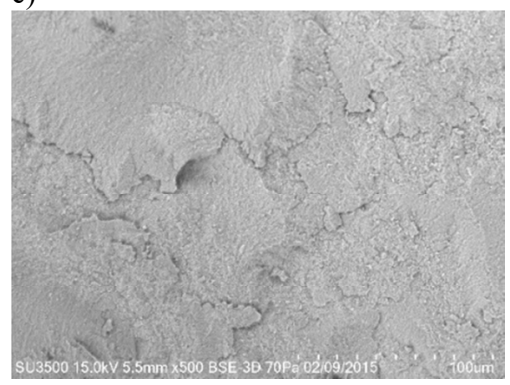

b)

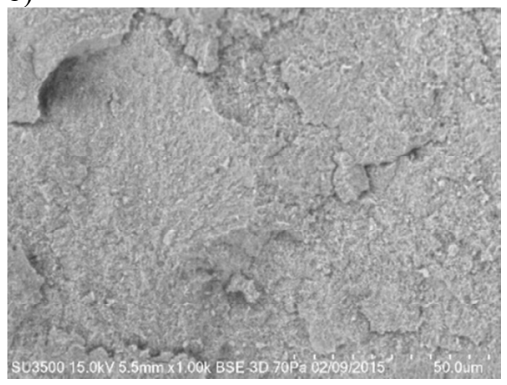

d)

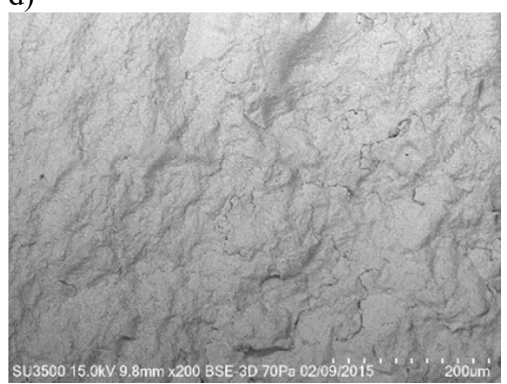

Fig. 4. Sample microscopic image of a zirconia sample at a larger scale: a) $1 \mathrm{~mm}$, b) $50 \mu \mathrm{m}$, c) $100 \mu \mathrm{m}$, d) $200 \mu \mathrm{m}$.

\section{Conclusion}

Advanced ceramics stabilized with various elements is a material increasingly being introduced to construction and operation in various areas of our lives. This material is characterized by high physicochemical properties. Literature review and analysis of own research have shown that the type of zirconium dioxide treatment applied has an impact on: repeatability of the sample geometry, strength of the material tested; however, the behavior of the manufacturers' procedures allows to obtain stable properties and high parameters. The performed three-point bending test for three different zirconium dioxide materials showed no significant differences in terms of mechanical strength; materials have similar strength. The results are characterized by high dispersion which could be caused by physicochemical properties and porosity of the material. Advanced ceramics used for research are characterized by the phenomenon of strengthening, which during the increase of load stops micro-cracks by expanding the $\mathrm{Zr}$ braces. The performed microscopic analysis showed that at the crack and crack propagation there is an increase in roughness, which could be caused by the sudden cleavage of the chemical chain of hardened (synthesized) material. The presented research is preliminary research that allows you to familiarize yourself with the material and determine the research potential, which is very large. Further research should be carried out due to the strength of the material, its durability, and analysis of the chemical chain or occurrence of the strengthening phenomenon. 


\section{References}

1. H.J. Conrad, W.J. Seong, I.J. Pesun, Prosthet. Dent. 98, (2007)

2. A. Della Bona, J.R. Kelly, J. Am. Dent. Assoc. 139, (2008)

3. A.R. Studart, F. Filser, P. Kocher, H. Lüthy, J. Gauckler, Dent. Mater. 23-2 (2007)

4. S. Scherrer, M. Cattani-Lorente, E. Vittecoq, F.de Mestral, J. Griggs, A. Wiskott, Dent. Mater. 27-2 (2007)

5. J. Tinschert, D. Zwez, R. Marx, K.J. Anusavice, J. Dent. 28, (2000)

6. M. Marrelli, C. Maletta, F. Inchingolo, M. Alfano, M. Tatullo, Int. J. Dent. (2013)

7. B. Ligaj, G. Szala, (Comparative analysis of fatigue life calculation methods of C45 steel in conditions of variable amplitude loads in the low- and high-cycle fatigue ranges, Polish Maritime Research, 19-4, 2012) 